\title{
Development of the Phonetic Skills in German as the Second Foreign Language on the Basis of the English Language
}

\author{
Liliya Ponomaryova, Elena Osadcha* \\ Oles Honchar Dnipropetrovsk National University, Ukraine \\ E-mail: lilienp@gmail.com \\ E-mail: *elena.osadcha@gmail.com
}

\begin{abstract}
Keywords: methods of teaching, second foreign language, phonetic skills, specific teaching conditions, facilitation, interference
\end{abstract}

\begin{abstract}
The problems of forming phonetic skills of the German language which is studied on the basis of the English language have been considered. The aim of this research is to make the comparative analysis of the phonetic aspects of the foreign languages that are taught one after another. There has been the attempt to analyze, generalize and systematize the material on the given topic which is presented in works in the German, English, Ukrainian and Russian languages on the main theoretical questions connected with the process of teaching the second foreign language. It was shown that while forming phonetic skills in German, it is necessary to give the characteristics to the phonetic, rhythmic and intonation peculiarities of both German and English; to point out the difficulties of mastering the pronunciation system of German, to develop the introductory course and the material for phonetic warming-up and to work out the algorithm of introducing a new sound.
\end{abstract}

\section{INTRODUCTION}

The development of the international contacts and the further globalization causes the situation when it is necessary to know not only one but several foreign languages to be able to function effectively in the contemporary society. That is why studying two foreign languages is foreseen by the program of training a specialist in many fields and by the curricula of most higher educational establishments in the world. The most commonly offered combination of the languages is English and German as foreign languages. Here, teachers of German face some problems connected with the interaction of these languages and it is worthwhile considering the issue of bilinguism, three-linguism and even polylinguism, because students in Ukraine speak Ukrainian and Russian as the native languages and learn two more foreign languages.

If bilinguism is defined as a co-existence of two languages, three-linguism and polylinguism are even more complicated phenomena, as this is a co-existence of three or more languages in speech and thinking sphere of an individual who chooses these languages in different communicative spheres. Bilinguism is the subject-matter of many sciences. It is studied in linguistics, psycholinguistics and social psychology. A lot of scientific research (L.A. Bulakhovskiy, Y.A. Zhluktenko, Y.M. Vereshchagin, A.D. Shweizer) are devoted to this aspect. The authors of the cognitive models who considered the transference of the rules of one language on the other language as a strategy of teaching a foreign language on the basis of another language are A. Knapp-Potthoff [1] and U.K. Yusupov [2].

N.I. Zhinkin proved experimentally that "teaching a foreign language will always be carried out in a native language, because a learner will never be able to distance from a native language, he will think in a native language until he learns a foreign language" [3]. All languages in a polylingual system don't play an equal role. "The main language is the language a person associates himself with. It is usually the first language a person learns this is the language of his environment" [4]. The conditions and the motives of using the second foreign language are very important because, as L.S. Vygotskiy considers, some difficulties can occur if the conditions don't guarantee an independent sphere of applying every language [5]. 
While teaching a foreign language in the situation of three-linguism, it is essential to avoid interference. "Interference is the process and the result of a language systems contacts, in which one system is dominant, causing effect of influence in the secondary language system" [6]. In this work we considered the ways of avoiding phonetic interference and reducing the influence of English which was taught previously to teaching German. Scientists who dealt with the questions of phonetic interference defined it as "the violation and distortion of a language system and norms of the studied language as a result of interaction of the phonetic systems of the first and a second language in a speaker's consciousness" [7].

There are some initial theoretical positions, general rules of teaching the German language on the basis of the English language. One of the main demands is to realize comparative (contrast) approach. There is a necessity to use the advantage of the interaction of a native language and foreign languages.

W. Veinreih thinks that while teaching two foreign languages, it is important to use "the description of the language system, the prediction of the most possible difficulties which can occur as a result of the languages contact, as well as the explanation of the characteristics of the behavior of bilingual native speakers which is connected with peculiarities of the first and the second language" [8].

In this work there was an attempt to study the specific features of teaching a foreign language not in the situation a bilinguism, but in the situation of polylinguism where two native languages are Ukrainian and Russian, and two foreign languages are learnt in a sequence. S.F. Shatilov distinguishes three stages of a skill formation: 1) preliminary; 2) stereotypical and situational; 3) variable and situational [9]

As a basis we take the scientific position of I.L. Bim who stated that "the experience of a learner in studying a native language and the first foreign language makes it possible to transfer the obtained knowledge and skills on learning the second language" [10] and make the comparative analysis of the phonetic systems.

So, the relevance of the work is that there has been made an attempt to present phonetic material for studying German in the situation of polylinguism in the system of linguistic, cultural and psychological and pedagogical tasks.

\section{THEORY}

\section{APPROACHES TO THE DEVELOPMENT OF THE PHONETIC SKILLS WHILE STUDYING TWO FOREIGN LANGUAGES}

As it is known, while teaching German as a foreign language after the English language, it is necessary to follow the general principles of teaching any foreign language. Although these principles have much in common, they have some modifications when applied to the second foreign language taking into consideration specific conditions of teaching, for example, three or four languages which are in contact in the process of teaching, substantial experience in studying a language which is not a native one $[10, \mathrm{p} .18]$. Forming the language system of a second foreign language system when the systems of two or three languages (native: Russian or/and Ukrainian and the first foreign language) have been formed, is a very complicated process directly touching the human consciousness. The second foreign language can be opposed to the other two, or all three languages can function as separate systems. Here is it necessary to consider the question of the language systems similarities, the level of mastering the languages by a three-lingual speaker, the sphere and the degree of using all three languages. It is almost predictable that as a result of the interaction of three languages the interference of different kinds, particularly in forming pronunciation skills, will occur. The task of a foreign language teacher is restricting and minimizing the negative influence of the interfering systems

The problem of studying two foreign languages, one of which is studied after the first one and on its basis, attracted the attention of many linguists and methodologists. The effective methods of teaching German, French and English as a second language have been developed by educationalists and methodologists such as I.L.Bim [10], I.O. Sitnikova [11] and H. Krumm [12]. However, not all 
the problems have been thoroughly investigated either in the methodological or in the linguistic context. The methodology of teaching phonetics of a foreign language is not exclusion.

It should be noted that though German and English are rather close and have much in common, the possibilities of facilitation - easy and positive transferring some concepts from one language to the other - in acquiring phonetic skills are insignificant because of the minimal coincidences in English and German.

The methods of forming phonetic skills traditionally include the exercises aimed it perceiving a model, identification a sound in a stream of speech and its imitation which can be accompanied by the instructions on the articulation movements. Later on, the pronunciation skills are intensively trained with the aim of making them automatic. According to the communicative theory of teaching foreign languages, perceiving and imitation of sounds goes on not in isolation, but in speech (rhymes, sayings, counts, verses, mini-dialogues and songs) $[10$, p. 36; 13, p. 146]. While presenting new lexical and speech patterns, their pronunciation is trained either with the help of visual aids or without them. From this point of view, the complex of the educational materials "Tangram"[13] is the most appropriate because it meets all the above-mentioned requirements. It was developed using the communicative activity approach to the methods of teaching German for foreigners, in which much attention is attached to the phonetic aspect of speech. However, it is intended for the multilingual audience irrespective of the specific features of the native and the basic foreign language.

At the stage of perceiving a new sound it is practically impossible to avoid the interference, however, it is possible to decrease and overcome it. [14]. For this purpose, at first it is necessary to show the differences in the articulation of sounds of the first foreign language and the second foreign language and to explain the peculiarities of the second foreign language with the help of the comparative exercises. Later, while training pronunciation skills, it is desirable to exclude the comparison.

While forming the intonation skills, comparison is not desirable. The phrase stress and the phrase melody pattern should be trained with the help of audio materials and by reading aloud. First of all, it is necessary to give students the opportunity of listening to the authentic speech using technical educational aids.

At the initial stage it is necessary to attach special importance to teaching phonetic aspects of speech, without any limitation by studying reading rules. Pronunciation skills must be supported by phonetic exercises and listening to authentic texts. While teaching a foreign language, intonation mistakes don't require much attention at this stage as they don't prevent communication.

The teaching experience shows that teaching phonetics, reading and spelling rules should be organized taking into account the knowledge the students obtained while studying the first language and their linguistic experience. Thus, the volume of the material studied and, respectively, the number of academic hours is reduced. Besides, teaching a second language it is necessary to mind a native language of the students (Ukrainian or Russian). It is worth mentioning the importance of the knowledge of the phonetic transcription students gained while studying the first language, the foreign articulation which was trained enough, well-developed phonematic hearing, the ability to write phonetic dictations and transcribe texts. All these skills make it possible to introduce the German sounds on the basis of comparing them to the sounds of the English language which was studied before.

In order to form the pronunciation skills it is necessary to develop the algorithm of introducing new sounds and give the characteristic to phonetic, rhythmic and intonation skills, to identify the difficulties of mastering the German pronunciation system, to work out the exercises including comparisons and imitation for the introductory course and the materials for the phonetic drills if they are not included in a textbook [11].

The articulation basis of a native language which is defined as a unity of habitual for the given language movements and positions of the speech organs greatly influences the pronunciation in a foreign language, leading to the irregularities which are referred to as "a foreign accent". The English articulation base already formed makes the similar influence on the pronunciation in 
German. Comparison of the distinguishing characteristics of the vowel and consonant phoneme system and the intonation of the Russian, Ukrainian and English languages which was made further, allows identifying the differences among the corresponding articulation bases of the languages and helps to acquire the right German pronunciation as much as possible free from a foreign accent.

The introductory course usually begins with a short talk about the similarities and differences of these languages in the field of phonetics, grammar and lexis. Unlike the similar course in the basic language, the theoretical knowledge in general phonetics should be reduced to minimum. Many phonetic phenomena in the German language are like those of the English language. For example, the pair division of the vowels of the front middle and upper rise, phonematic differences of stressed vowels which may be long and short, the absence of consonant palatalization before the vowels of the first row and many others.

In the German language there is no regressive assimilation by the voiced sounds, in other words, making a voiceless consonant similar to a voiced consonant. This phenomenon is not very common in English. However, along with the similar phenomena in the phonetic systems of both languages, the German language has its peculiarities which should be taken into consideration while designing a course, namely, the prevalence of a middle-tongue articulation over the back-tongue articulation. Labialized articulation prevails non-labialized, the lip articulation is not relaxed. If the introduction of the German sounds goes without a comparison, the articulation skills are transferred from the basic language to the second one which is not desirable

\section{RESULTS}

\section{IMPORTANCE OF PHONETIC SYLLABLE DIVISION}

The analysis that has been undertaken allowed distinguishing some aspects that are important in teaching German and English phonetics. One of them is syllable division. The principle of the syllable division in both languages mainly coincides. In both English and German the syllable mark goes between one vowel and the following consonant, between two root consonants and between the last of the cluster of consonants. In German: sagen [za:-gən], fragen [fra:- gən]; in English: window [win - dow], graphic [grae - fik].

Unlike in Russian, in the German and in the English language the syllable border is after the short stressed syllable before the following consonant which closes the syllable. It is worth noting that in the German language the border of a syllable is just after a long vowel which does not present any difficulty for native Ukrainian and Russian speakers. However, after a short vowel the border lies after the first consonant following after it, which is unusual and presents the major difficulties in dividing a word into syllables: Waffe [vaf - ə], Ecke [ek - ə], Masse [mas - ə], Finger [fin - ə], immer [im - ər] [15]. It is also characteristic for the English language. Compare: city [sit-i], guinea [gin -i].

There are many similarities in stresses in a word. In German stress mainly falls on the root syllable. The German stress has a dynamic and melodic character as the tone rise accompanies the increased intensity of a stressed syllable. The difference between stressed and unstressed syllables in the German language is more expressed than in the Russian, Ukrainian and English languages. In German and in English stress helps to differentiate between the meanings of the word, in other words, performs the semantic function. For example, in German: 'durchschneiden (cut) and durch'schneiden (cross), Genus (gender) and Genuss (pleasure); in English: 'desert (area of sand) and de'sert (abandon).

\section{THE SYSTEM OF PHONEMES IN GERMAN AND ENGLISH}

The analysis of the phoneme system of German and English, the types of the intonation in different kinds of sentences and typical mistakes shows that not all the phonemes and intonations in a sentence are mastered by the students similarly, so they should be introduced in a certain sequence:

a) similar [f, v, p, k, g, n, i:, I, o, o:];

b) relatively similar $\left[\mathrm{t}, \mathrm{d}, \mathrm{n}, \mathrm{l}, \mathrm{s}, \mathrm{z}, \int \mathrm{t} \mathrm{t}, \mathrm{u}, \mathrm{v}, \mathrm{\partial}\right]$; 
c) different in pronunciation [w, h, r, x, ts, ç, pf, ø, œ, y:, y] vowels and consonants. These are the phonemes that should be paid special attention to.

\section{Vowel Phonemes}

In the German language like in the English language, there are much more vowel phonemes than in Russian or Ukrainian, which can be explained by the meaning distinguishing role of vowels, that in Russian and Ukrainian remain within the shades and positional variants of one phoneme. Short and long, open (wide) and closed (narrow) vowels can be distinguished. Besides pure vowels (monophthongs), in German there are three diphthongs which are descending like in English. The articulation of the diphthongs ae and ai which are conveyed by the letter combinations ei and ai is composed of the articulation [a] and the following gliding from [a] to [e]. As the lower jaw goes a bit down when the German [a] is pronounced, it especially influences the difference between the German diphthongs with the first element [a] - [ae] and [ao] - and the correspondent English diphthongs.

German vowels are characterized by the following features: like the English ones they are tenser than in Russian and in Ukrainian; while pronouncing German long vowels there is no glide. None of the German monophthongs has the character of a diphthong like in Russian [e], [o] and in English [i:], [u:].

Vowels [y:], [y] and [ø:], [œ] are the most difficult for pronouncing as the combination of the articulation movements is totally uncommon for both Russian and Ukrainian, as well as for English articulation basis. For labialization not to be accompanied by the involuntary back language protruding, it is necessary for the tip of the tongue to touch the upper teeth. It is essential to start working at the unusual movement combination of the speech organs with the tongue positioning for [i:] or [i] with the following labialization, or vice versa with the following changing the tongue position from [u:] to [i:] or from [u] to [i].

To practice the pronunciation of vowels [y:], [y] and [ø:], [œ], the following exercises are recommended:
[e:] -------- [ø:]
[e:rə] [ø:rə]
[o:] -------- $[\varnothing:]$
[ø:]
[o:fən] [ø:fən]
[ø:1]

While pronouncing the neutral vowel [ə], the articulation movements are expressed very slightly. The vowel is not a phoneme, but a shade of a phoneme. It some positions it is close to [e:], in the others - to $[\varepsilon]$.

It is found only in the unstressed position, in prefixes, suffixes and endings. Unlike in German, English vowel [ə], which is found also in unstressed syllables and has its shades, is an independent phoneme.

At the beginning of a word, in a part of a compound word and after a prefix, German vowels are pronounced with so called Knacklaut, which causes certain difficulties with students. Compare:

Рус. Он инженер. Укр. Він інженер.

Анг. He is an engineer. Нем. Er ist Ingenieur.

This phenomenon is not common for Russian but something similar can be found in the negative answer "ne-a". For two vowels not to merge, the sound [a] is pronounced with the similar Knacklaut.

\section{Consonant phonemes}

The compositions of the consonant system in German, English, Ukrainian and Russian do not coincide. Besides, there is no palatalization in German and English which is characteristic for Russian and Ukrainian. There are no analogues in Russian to some German consonants: $[\mathrm{x}]$ and [h]. Only in German, a small tongue (lat. uvula) acts like an active organ while pronouncing glottal [x]. In both German and English there is consonant [h] which refers to pharynx consonants. There is not a similar sound in Russian. Sometimes it is replaced by the voiced pharynx consonant of Ukrainian. It gives an approximate sound effect, but this replacement is nit correct because [h] is German is voiceless. The noise of consonant $[\mathrm{h}]$ is almost unheard, however, $[\mathrm{h}]$ performs an important semantic function as thanks to this phoneme the meaning of a word beginning with a vowel with 
Knacklaut or without it is distinguished: [i:r] - a personal pronoun you, [hi:r] - adverb here; [a:r] an eagle, [ha:r] - hair.

Only in German there are mid-tongue glottal consonants, voiced and voiceless [c] и [j]. Russian, Ukrainian and English sounds close to [j] are sonants. The pronunciation difficulties of these consonants are connected with the technical side of reading, for example, German [j] is pronounced by students as the English sound [d]. Voiced consonants [d] and [3] are found only in the words borrowed from English and French. In these words consonants [d] and [3] are conveyed with letters $g$ and $\mathrm{j}$.

While lowering soft palate, a back-tongue sonant is formed with lowering the soft palate, which is characteristic only for German and English. As labial-glottal voiced consonant [v] in German coincides with Russian consonant [v] and differs from the English only by a degree of tension, the influence of English pronunciation of this vowel does not have any long-lasting effect.

Tremulous sounds which used to be an inseparable part of the German phonetic system don't have any practical importance in today's everyday speech practice. The front-tongue $[\mathrm{r}]$ or uvular $[R]$ which used to be considered the obligatory variants of the phoneme [r], can be replaced with other variants of realization, most often in a fricative form [ $\gamma][15$, p. 33]. In English the consonant [r] refers to the front-tongue apical sonants and is not like either German or Russian tremulous [p]. In the German language it is characteristic for consonant «r» to be voiced when it is in the ending «er», in unstressed prefixes «zer», «er-», «ver-» and after long vowels, for example: flur [flue], ergriffen [əugrifən], verstehen [fə๖fte:ən], zerfallen [ tsəufalən ] and so on.

It is worth paying attention to the fact that in English voiced consonants at the end of the word never become voiced unlike in German. Compare Tag [ta:k], Bund [bunt] and $d o g$ [dog], dad [dæd] [15].

\section{DISCUSSIONS}

In the situation of three or four languages functioning, the mechanism of the mutual influence of the languages is becoming more complex as there function four language systems $[12,13,15]$.

It is necessary to have sufficient knowledge of the causes of prosodic interference, its sources and conformities to prevent or remove possible violations of the prosodic foreign speech organization in the communicative situation of bilinguism [15, p. 171]. You should pay special attention to the influence of the English intonation on the German intonation which is characterized by the absence of long intervals between the syllables with strong stresses and unstressed syllables with a completely different rhythmic structure. In all affirmative sentences in Russian and Ukrainian as well as German and English, the tone at the end of the sentence goes down. The descent in the German sentence begins from the last syllable which is logically stressed. Compare:

German: Entschuldigung, ich suche ein Fahrrad.

English: Sorry, I am looking for bicycles.

Fahrräder finden Sie im Erdgeschoss.

You can find them on the first floor.

In interrogative sentences without interrogative words, the stressed syllable of a word which has the most important meaning is emphasized by the strengthened stress. This strengthened stress is accompanied either by a considerable rise or, on the contrary, a fall of the tone of a stressed syllable. By the end of the sentence the tone rises not only on the stressed syllables but on the afterstressed syllables. In Russian the tone rise accompanies only logically emphasized word whereas in English an interrogative sentence has a rising melody, a high tone of the first stressed syllable, soft tone falling on every following syllable and tone rising only on the last stressed syllable. It is not so abrupt as in German. Compare:

German: $\downarrow$ Willst du dieses Buch lesen?

English: $\uparrow$ Do you want to read this Book?

It's necessary to mention the intonation in an interrogative sentence with an interrogative word because unlike in the Russian language, the word doesn't receive a strong stress. As a rule, the predicate is emphasized by the strong stress. In English an interrogative sentence with an interrogative word is pronounced with the descending intonation, in other words, with a gradual fall 
beginning with the first stressed syllable and an abrupt fall on the stressed syllable till the lower border of a voice range; the following syllables are pronounced on the same level. Compare:

German: $\downarrow$ Was machst du heute Abend?

English: $\uparrow$ What are you doing tonight?

\section{CONCLUSIONS}

The peculiarities of teaching the German language as a second language on the basis of the existing methods are an aspect that should be taken into account by a foreign language teacher. It is necessary to understand the role of the methods of teaching, the pronunciation aspect of speech in the context of communicative and cognitive approach. The comparison of the phonemes of the German language and the German intonation in the basic types of the sentences with the phonemes and the intonation of the English language as well as the Russian and the Ukrainian languages helps students to develop the skills of correct pronunciation. There are some factors that make it difficult to master the German phonetics and those that facilitate it. Studying phonetics, reading and writing rules should be conducted taking into account the knowledge that students received while studying the first language and their linguistic experience. Thus, the reduction of the volume of the studied material and, as a result, academic time is achieved. The specific conditions of teaching due to the presence of four languages - German, English, Russian and Ukrainian - that are in contact in the process of studying are known to play an important role.

We should emphasize that the effectiveness of classes, students' level of mastering the language material and their participation in the communicative process depend on the rational methods of studying the phonetic system of the second language. Many phonetic phenomena of the German language are similar to those of the English language. However, along with the similar phenomena in the phonetic systems of both languages, the German language has its special characteristics and differences which should be taken into consideration while designing the educational course.

While teaching German as the second language after English it is necessary to follow the general principles used in the process of teaching any foreign language. Having a lot in common, they still have some modifications connected with specific conditions of studying, for example, four or three languages interacting within the process of language studying. To develop correct pronunciation skills it's necessary to design a certain algorithm of introducing the sounds which are significantly or totally different from the sounds of the first language, to prepare the exercises based on comparison and imitation for the introductory course and the materials for the phonetic warming-up.

A special attention should be paid to the influence of the English intonation on the German intonation with the aim of removing possible difficulties in the prosodic organization of the speech in a foreign language that bilingual students may have in the process of communication.

\section{References}

[1] A. Knapp-Potthoff, K. Knapp, Fremdsprachenlernen und lehren, Mainz, 1982.

[2] U.K.Yusupov, Comparative linguistics as in independent disciplines, Nauka, Moscow, 1988.

[3] N.I. Zhinkin, Mechanisms of speech, Moscow, USSR, 1958.

[4] M. Siguan, U.F. Makki, Education and bilinguism, Pedagogika, Moscow, USSR, 1990.

[5] L.S. Vygotskiy, On the problem of polylinguism, Pedagogika, Moscow, USSR, 1983, v.3, p. 328-337.

[6] G.M. Vishnevskaya, Bilinguism and its aspects, Ivanovo, Russia, 1997.

[7] N.A. Lyubimova, Phonetic interference, LSU, Leningrad, USSR, 1985.

[8] W. Veinreih, Speech contacts: state and problems of research, Kiev, Ukraine, 1979.

[9] S.F. Shatilov, Methods of teaching German in the secondary school, Prosveshcheniye, Moscow, USSR, 1986.

[10] I. Bim, The concept of teaching the second foreign language (German on the basis of English), Tver, Russia, 2001. 
[11] M. Guz, I. Sytnikova. Phonetics. Read and speak in German, St. Petersburg, Russia, 2005. [12] H. Krumm, Sprachenpolitik und Mehrsprachigkeit, in: Hufeisen, B., Neuner, G. Mehrsprachigkeitskonzept - Tertiärsprachen - Deutsch nach Englisch. - Europäisches Fremdsprachenzentrum. - Strasbourg: Council of Europe Publishing, 2003, p. 35.

[13] I. Alke, R.-M. Dallapiazza, E. von Jan, D. Maenner, Tangram. Deutsch als Fremdsprache, 2006.

[14] N. Kulchutska, Peculiarities of interference in the process of teaching English as the second language at the philological higher educational establishment, Berdyansk, Ukraine, 2010, p. 241245.

[15] T. Chevanina, Prosodic peculiarities of reading and speaking in a multi-lingual environment (Russian, French and Russian threelinguism), Volgograd, Russia, 2008.

[16] R. Potapova, G. Lindner, Peculiarities of German pronunciation, Moscow, 1991. 